\title{
Precocious weaning and changes in social variables during prepuberty affect cocaine reinforcing properties in adult mice
}

\author{
GIOVANNI LAVIOLA and GIACOMO DELL'OMO \\ Istituto Superiore di Sanità, Rome, Italy
}

\begin{abstract}
The aim of this study was to determine whether manipulation of weaning time and of social variables during prepuberty in mice would account for the individual features of behavior that are correlated with the abuse of drugs. This issue was addressed by searching for differences in cocaine effects in the adult offspring of both sexes from outbred Swiss CD-1 mouse litters. On Postnatal Day 15, litters were split into two halves, with one half litter weaned (precocious weaning, PW) while the other remained with the dam (regular weaning, $\mathrm{RW}$ ). At the same time, pups in each half litter were assigned to either a unisex or a mixed-sex rearing condition. From Postnatal Day 25 to adulthood (time of testing, 70 days), all mice were rehoused according to both sex and weaning. Both adult PW male mice and unisex-reared animals of both sexes were, in general, more active than corresponding controls. In a placeconditioning schedule, aimed at assessing the reinforcing properties of cocaine $\mathrm{HCl}$ (two drug pairings; $0,1, \mathrm{or} 5 \mathrm{mg} / \mathrm{kg}$, i.p.), mixed-sex mice of both sexes were readily conditioned by the drug. Time of weaning determined the direction of the conditioned performance. In fact, although RW mice in this specific paradigm showed a reduction of time spent in the drug-paired area, subjects weaned precociously developed a quite clear conditioned place preference in a dose-dependent fashion. Interestingly, irrespective of their weaning history, cocaine failed to induce conditioning in animals that had undergone sexual segregation during development. These differential cocaine effects (1) suggest alterations in the function of mesolimbic and nigrostriatal DA systems linked to subtle changes in social stimulation during development, and (2) may be associated with an acquired predisposition to exhibit an individual responsivity to drugs of abuse.
\end{abstract}

There is a growing body of evidence in animal models investigating the role of acquired experiential deviations (for the literature and a discussion, see Laviola \& Alleva, 1995, and Terranova \& Laviola, 1995) in brain and behavior regulations occurring early in life, that is, during a period of organization and as a consequence of increased vulnerability of CNS structures (Greenough, Whiters, \& Wallace, 1990). In this regard, Bowling, Rowlett, and Bardo (1993) recently reported that with environmental enrichment during development the response to amphetamine in adult rats can increase. In addition to the manipulation of spatial complexity of the rearing environment, the changes operated by these authors varied along a social dimension as well. Social factors have long been known to influence the effects of dopamine agonists and antagonists (for mixed results obtained with individual housing, see, for example, Bowling \& Bardo, 1994; Boyle,

This research was supported as a prosecution of the Subproject on Behavioral Pathophysiology (Project on Noninfectious Pathology) supported by the Istituto Superiore di Sanità, Rome, Italy, and by the Italian National Health Service project "Risk factors in maternal and child health." We acknowledge Flavia Chiarotti for her expert statistical advice and the help of Carla Tascone in formatting the manuscript. Correspondence should be directed to G. Laviola, Section of Behavioral Pathophysiology, Laboratorio di Fisiopatologia di Organo e di Sistema, Istituto Superiore di Sanità, viale Regina Elena 299, I-00161 Rome, Italy (e-mail: laviola@ iss.it).
Gill, Smith, \& Amit, 1991; Sahakian, Robbins, Morgan, \& Iversen, 1975).

A series of recent studies have also shown that a different type of manipulation of social variables, namely sexual segregation in infancy can qualitatively affect some aspects of the animal's behavioral repertoire or its response to psychoactive drugs in adulthood, while not altering neurobehavioral development (Alleva, Caprioli, \& Laviola, 1986; Laviola \& Loggi, 1992; Loggi, Dell' Omo, \& Laviola, 1996). As for the mechanisms that may be responsible for the differences related to the sex of littermates, one working hypothesis includes a joint action of at least two factors (Laviola \& Loggi, 1992), namely: (1) variations of the dam's behavior as a function of litter gender composition (Alleva, Caprioli, \& Laviola, 1989; Moore \& Morelli, 1979), and (2) changes in the nature of interactions among siblings (e.g., different levels of social grooming or play behavior) as a function of sex of littermates (Denenberg \& Morton, 1964; Gray, Lean, \& Keynes, 1969). In a series of developmental investigations, various degrees of sexual segregation of infant mouse litters were related to different levels of both solitary and social play behavior (Laviola \& Alleva, 1995; Terranova \& Laviola 1995), as well as to profound changes in both activity and novelty-related behaviors at the adult stage (Laviola \& Loggi, 1992; Loggi, Dell'Omo, \& Laviola, 1996). 
As reported above, the "organization" of monoaminergic functions in the CNS and the adult response to psychoactive drugs appear to be responsive to developmental manipulation of spatial complexity or social characteristics of the rearing environment (Bowling et al., 1993; see also Matthews, Wilkinson, \& Robbins, 1996). This view suggests that noradrenergic and dopaminergic regulations mature early in ontogeny (see Laviola, Renna, Bignami, \& Cuomo, 1988), and that these CNS systems are involved in the mediation of affiliative social behaviors early in development (Kehoe \& Boylan, 1992). Overall, these findings are consistent with the proposition that changes in the characteristics of early social environment are able to modulate function at the level of specific neurochemical CNS systems. Accordingly, it should be kept in mind that environmental factors may be important in the genesis of functional CNS disorders (Bowling \& Bardo, 1994; Sahakian et al., 1975; see also Winn, 1994).

The general hypothesis driving the present experiment was that providing prepubertal mice with different kinds of family units to be raised in would affect specific patterns of adult behavior thought to reflect changes in responsivity to cocaine (Bowling et al., 1993; Laviola, 1994). Since cocaine is also one of the most potent addictive agents, whose reinforcing properties rely on mesolimbic dopaminergic mechanisms, the positive reinforcing or aversive effects produced by the drug were measured by using a short repeated schedule of place conditioning (see Laviola, Dell'Omo, Alleva, \& Bignami, 1992).

Moreover, with the aim of investigating the direct effects of early weaning, a group of animals, which had been precociously separated from their mothers on Postnatal Day 15, were also tested (for the literature and discussion on this, see the Method section below). The inclusion of this experimental group also allowed us to separate the potential carryover effects of the two factors discussed above, namely, biased maternal care and changes in social interactions between littermates as a function of type of family unit.

\section{METHOD}

\section{Animals, Breeding, and Rearing Conditions}

Mice of an outbred Swiss CD-1 strain, purchased from Charles River Italia (Calco, Italy), were used as subjects. Upon arrival, they were housed in standard conditions (temperature $21^{\circ} \pm 1^{\circ} \mathrm{C}$, relative humidity $60 \% \pm 10 \%$ ), with lights on from 9:30 a.m. to $9: 30 \mathrm{p} . \mathrm{m}$. Males and nulliparous females were housed separately in groups of 8 in $42 \times 27 \times 15 \mathrm{~cm}$ Plexiglas boxes with sawdust as bedding and a metal top. Pellet food (Enriched Standard Diet purchased from Mucedola, Settimo Milanese, Italy) and water were continuously available.

After 2 weeks, breeding pairs were formed and housed in $33 \times$ $18 \times 14 \mathrm{~cm}$ boxes. Females were inspected daily at 10:00 a.m. for the presence of vaginal plug (Pregnancy Day 0 ) and for delivery (Postnatal Day 1). At birth, litters were reduced to 8 pups, 4 males and 4 females. On Postnatal Day 15 , each litter was divided in half; one half were randomly assigned to a precocious weaning (PW, mother removed) group, while the other half were kept with the mother and transferred to a new cage (regular weaning, or RW). At the same time, the sexes were segregated (see Laviola \& Loggi, 1992; Terranova \& Laviola, 1995): each half litter was randomly assigned to either a unisex (all males and all females) or a mixedsex family unit condition. On Postnatal Day 25 , mice in each of the two weaning conditions were rehoused according to sex in $42 \times 27$ $\times 15 \mathrm{~cm}$ Plexiglas boxes (4 individuals per cage).

Postnatal Days 14-25 were chosen for the manipulation of social variables because they delimit a critical period in development during which the future pattern of social response in mice is determined (Denenberg \& Morton, 1964; Hayashi \& Kimura, 1978). In addition, significant changes in social interactions have been associated with prominent carryover consequences on a series of behavioral and physiological parameters (Loggi et al., 1996; Terranova \& Laviola, 1995). To minimize distress, the precocious weaning procedure was begun when all pups in a litter were able to take solid food, and were presumably able to compensate for the suppression of milk intake (see Terranova \& Laviola, 1995). Milk cream in a dish and food pellets were put on the flocr of the cage on Postnatal Days 14-16, in order to limit the potentially stressful experience related to the sudden removal of the dam and consequent abrupt suppression of food intake. The first appearance of weaning behavior and eating of solid food are normally observed around Postnatal Days 16-17 (see Smith, 1991; Terranova \& Laviola, 1995). Moreover, it has been reported that weaned mice can subsist on solid food as soon as their eyes open (around Postnatal Day 15), and a series of previous studies from our group (Terranova, Alleva, \& Laviola, 1994; Terranova \& Laviola, 1995; Loggi et al., 1996) have shown that there are no significant carryover effects of precocious weaning on body weight.

The animals were classified as adults when they reached Postnatal Day $70 \pm 1$. All mice were used only once. Each single treatment group was represented by 8 animals, with only 1 animal per original litter contributing to each mean.

\section{Apparatus and Procedures}

When they became adults, the animals were weighed and randomly assigned to one of the following treatments: cocaine hydrochloride (Merck, 223 Darmstadt) in physiological saline vehicle ( 1 or $5 \mathrm{mg} / \mathrm{kg}$ ) or saline $(\mathrm{NaCl} 0.9 \%$ ) given i.p. in a volume of $0.01 \mathrm{ml} / \mathrm{g}$ body weight, according with dosages and schedule of exposure suggested in the literature (Laviola et al., 1992). Tests were performed between 9:30 and 6:00 p.m. The apparatus (four identical units) was similar to Laviola et al.'s (1992) and was provided with an automatic data recording system (custom made by Elma System, I-00100 Rome, Italy), which measured the time each animal spent in each compartment. Data for each subject in each session were stored in a file for direct transfer to the system used in statistical analyses. Briefly, it consisted of a rectangular Plexiglas chamber $(34 \times 32 \times 30 \mathrm{~cm})$ with two compartments separated by a wall, which could be used either with or without an inverted Ushaped $4 \times 7 \mathrm{~cm}$ opening. Two cues, one visual (white vs. black internal surface) and one tactile ("wide-mesh" vs. "narrow-mesh" floor), were associated with each of the two compartments. The floors of these compartments were engraved with incisions of $2-\mathrm{mm}$ width and depth separating flat square portions of $7 \times 7 \mathrm{~mm}$ in the white "wide-mesh" compartment and of $2 \times 2 \mathrm{~mm}$ in the black "narrow-mesh" compartment.

Preliminary data from our laboratory indicated that naive adult mice show a slight natural tendency to spend more time in the black compartment than in the white compartment when given freechoice access to the entire apparatus for $10 \mathrm{~min}$ (see also Laviola, Dell'Omo, Alleva, \& Bignami, 1994). The procedure most frequently adopted in the literature is to pair the drug administration almost always with the least preferred side (Bardo, Neisewander, \& Miller, 1986; Lett, 1988). Thus, animals were conditioned in the white side with either cocaine or saline and given preference tests on the days intervening between conditioning trials. Each conditioning 
trial consisted of a 2-day procedure in which the animals were trained or tested:

Day 1, habituation session: Inexperienced animals were allowed to explore the apparatus for $10 \mathrm{~min}$ between 9:30 and 11:00 a.m. The habituation trial was also aimed at avoiding any disturbance due to the combination of the novelty of the apparatus and the effects of cocaine at the time of drug injection. No formal record of individual preference was taken.

Day 1, conditioning training: At the end of the previous session, the animals were injected with either saline or cocaine at doses of 1 or $5 \mathrm{mg} / \mathrm{kg}$ and then confined immediately in the white and less preferred compartment of the apparatus for $30 \mathrm{~min}$ (for literature and discussion also on the efficacy of one single drug pairing to obtain a place conditioning profile, see Bardo et al., 1986; Laviola et al., 1992; Laviola et al., 1994). At the end of the exposure, the mice were put into a Plexiglas box that was similar to their home cage and placed on a Varimex activity meter apparatus (Columbus Instruments, $\mathrm{OH}$ ), where activity counts were recorded at 6-min intervals during a single 30 -min session.

Day 2, conditioning training: At the same time as on the day before, all subjects received a saline injection before being confined in the opposite compartment for $30 \mathrm{~min}$.

Day 2, conditioning test: Four hours after the end of the previous session, the first place conditioning assessment was conducted in a drug-free state, by placing uninjected mice in the white compartment with their heads pointing away from the black compartment, and allowing them free access to both end compartments during a 10 -min test.

On Days 3 and 4, the procedure described for the first 2 days of the schedule was repeated without the activity measurements in the Varimex apparatus. The experimental design was counterbalanced in order to equate the representation of various groups at different test times.

\section{Statistical Analysis}

The data were analyzed by means of a mixed-model analysis of variance (ANOVA) considering all fixed variables $(2 \times 2 \times 2 \times$ 3 ) in addition to the litter random variable (Abbey \& Howard, 1973; Chiarotti, Alleva, \& Bignami, 1987), with time of weaning (regular vs. precocious), sex (males vs. females), prepubertal sexual seg- regation (segregation: mixed sex vs. unisex), and drug treatment as between-subjects factors. In the case of the Varimex activity data, the ANOVA included the within-subjects (repeated measures) variable of five 6-min blocks. Post hoc comparisons within logical sets of means were performed using Tukey's HSD test, whose use is permissible or even recommended in the absence of significant main or interaction effects in the ANOVA, in order to minimize both Type I and Type II errors (Wilcox, 1987, pp. 187-189).

\section{RESULTS}

\section{Body Weight}

Body weights were assessed, and, as expected, the two sexes differed $[F(1,168)=120.02, p<.01]$, with females weighing generally less than males, while no significant carryover effects of either segregated rearing or the weaning variable were found.

\section{Activity}

Activity in a Varimex apparatus upon acute cocaine exposure was assessed on Day 1 of Phase 2 of the schedule. As expected, acute cocaine administration [treatment, $F(2,168)=8.63, p<.001]$ induced a clear-cut dosedependent increase of locomotion (sal $111.7 \pm 3.4$, coc $1 \mathrm{mg} / \mathrm{kg} 120.0 \pm 3.2$, coc $5 \mathrm{mg} / \mathrm{kg} 136.6 \pm 2.7$ ). Prepubertal sexual segregation also had carryover effects on activity levels $[F(1,168)=10.9, p<.001]$, with animals reared unisexually being in general more active than mice reared in mixed-sex groups $(131 \pm 2.6$ vs. $114 \pm$ 2.6). Moreover (see Figure 1), the sex of subjects and time of weaning interacted with repeated measures $[F(4,672)=$ $3.63, p<.01]$, with males weaned precociously being significantly more active than both similarly weaned females and regularly weaned males on the second and third 6-min blocks $(p s<.05)$ of the session.

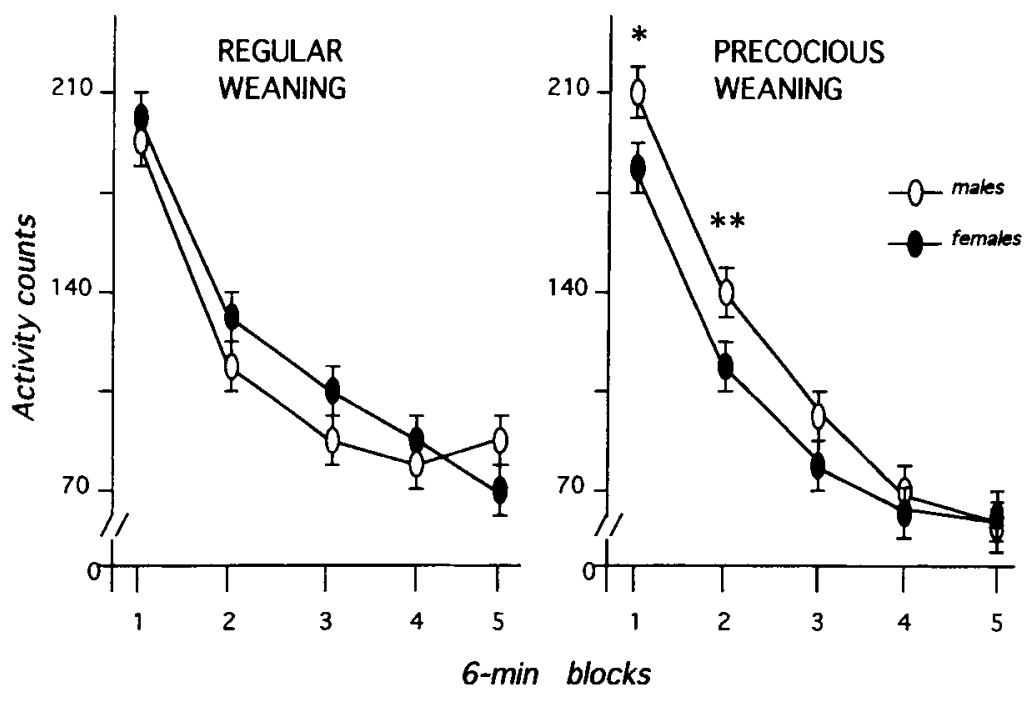

Figure 1. As assessed in a Varimex apparatus (single 30-min session), mean locomotion $( \pm S E M)$ of regularly and precociously weaned adult male and female mice ( $N=48$ ) immediately after being confined for $30 \mathrm{~min}$ in the white (drug-paired) side of a place-conditioning apparatus (drug state, Day 1 of the schedule); data are collapsed over drug treatment. ${ }^{*} p<.05 ;{ }^{* *} p<.01$. 


\section{Latency to Leave Apparatus}

With regard to latency to leave the drug-paired area of the apparatus as assessed on Days 2 and 4 of the schedule (drug-free state), no significant effects were found for latency to leave the white paired area during the first behavioral assessment performed on Day 2. In the second assessment, performed on Day 4, however (see Table 1), a sex $\times$ weaning interaction appeared $[F(1,168)=5.02$, $p<.05]$, with male mice weaned precociously leaving the paired area of the apparatus later than both similarly weaned females and regularly weaned males $(p<.05)$. Moreover, a higher level interaction of sex, segregation and treatment $[F(2,168)=4.89, p<.01]$, also emerged in the ANOVA (see Figure 2), with females reared unisexually and injected on the day before with saline showing a significantly shorter latency to leave the paired area than both similarly injected males reared unisexually and mixed-sex females $(p s<.05)$.

With respect to drug effects, cocaine treatment given $24 \mathrm{~h}$ before showed a carryover influence by reducing dose-dependently the response latency of mixed-sex reared animals. This was significant with the high $(5-\mathrm{mg} / \mathrm{kg})$ cocaine dose $(p<.05)$ in the mixed-sex female group when compared with corresponding controls, whereas the performance of mixed-sex males was unaffected. With respect to mice reared unisexually, cocaine administered $24 \mathrm{~h}$ previously had a mixed profile of effects by increasing significantly, with the $1-\mathrm{mg} / \mathrm{kg}$ dose, the latency of females reared unisexually when compared with both the control and the $5-\mathrm{mg} / \mathrm{kg}$ groups $(p \mathrm{~s}<.05)$.

\section{Acquisition}

The acquisition of place conditioning was assessed on Days 2 and 4 of the schedule (drug-free state). With respect to the time spent in the drug-paired compartment, as measured during the first assessment of place conditioning (Day 2 of the schedule), a significant main effect of segregation $[F \mathrm{~S}(1,168)=6.127, p<.01]$ and a segregation $\times$ weaning interaction just missing significance $[F(1,168)=3.483, p=.06]$ suggested that mice reared in sexual segregation and weaned regularly generally spend less time in the drug-paired compartment than do the other three groups. No significant conditioning drug effects were evidenced during this first assessment (see Figure 3, upper panel).

Table 1

Mean Latency $( \pm S E M)$ for Adult male and Female Mice to Leave the Bright White (Drug-Paired) Area of the Apparatus in the Second Place-Preference Test (Drug-Free State, Day 4 of Schedule)

\begin{tabular}{lccccc}
\hline & \multicolumn{2}{c}{ Regular Weaning } & & \multicolumn{2}{c}{ Precocious Weaning } \\
\cline { 2 - 4 } & $M$ & $S E M$ & & $M$ & $S E M$ \\
\hline Males & 5.78 & 0.45 & 7.48 & $0.45^{*}$ \\
Females & 6.62 & 0.66 & 6.02 & 0.49 \\
\hline
\end{tabular}

${ }^{*} p<.05$ for the comparison between regular and precocious weaning conditions within the male group as well as for a comparison between male and female mice within the precocious weaning condition. The animals were the same as those used in Figure $1(N=48)$.
In the second place-conditioning test, performed on Day 4 of the schedule (see Figure 3, lower panel), a main effect of weaning $[F \mathrm{~s}(1,168)=5.84, p \mathrm{~s}<.01]$ was evident. This was in the absence of the simple effects of either segregation or treatment. Specifically, mice weaned regularly spent less time in the paired compartment than did those weaned precociously. In addition, there was a weaning $\times$ segregation $\times$ treatment interaction $[F(2,168)$ $=3.09, p<.05]$ consisting of a dose-dependent reduction of time spent in the drug-paired area by mixed-sex mice weaned regularly $(p<.01$ for the $5-\mathrm{mg} / \mathrm{kg}$ dose vs. corresponding controls, see Figure 3, lower panel on the left). Conversely, precocious weaning was responsible for the production of a quite opposite profile $(p<.01$ for the $5-\mathrm{mg} / \mathrm{kg}$ dose vs. controls), which suggests the acquisition of a conditioned place preference. As a consequence, with the $5-\mathrm{mg} / \mathrm{kg}$ cocaine dose, the difference in performance between the two weaning groups also reached significance $(p<.01)$.

Finally (see Figure 3, lower panel on the right), the animals reared in unisexual family units completely failed to show any conditioning effects of the drug in either direction. Thus, within the precocious weaning group, the performance of these animals with the higher drug dose $(p<.05)$ was significantly different from that of the corresponding mixed-sex group.

\section{DISCUSSION}

The main results of the study reported above can be briefly summarized as follows:

1. Adult mice of both sexes reared during prepuberty within unisexual family units showed higher baseline levels of activity than did corresponding animals reared in a mixed-sex condition.

2. Males weaned precociously were more active than those weaned regularly. No such difference was found for females.

3 . The latency of the precociously weaned males to leave the drug-paired area of the place-conditioning apparatus was longer than that of both similarly weaned females and males weaned regularly.

4. Precocious weaning was responsible for the development of a cocaine-induced conditioned place preference in mixed-sex subjects, whereas mice weaned regularly spent less time in the same compartment.

5. Interestingly, irrespective of the weaning factor, animals reared in unisexual family units failed to show any response change to the conditioning drug effects.

A few comments should be made on some aspects of these results:

First, the finding of a cocaine-related conditioned place aversion in the mixed-sex and regularly weaned group was intriguing but not unexpected in view of the available literature (see below). One simple explanation for such results is that the immediate drug effects were rewarding, but that these changes were followed by delayed aversive effects (Sherman, Roberts, Roskam, \& Holman, 1980), and that the mice associated the latter effects with 


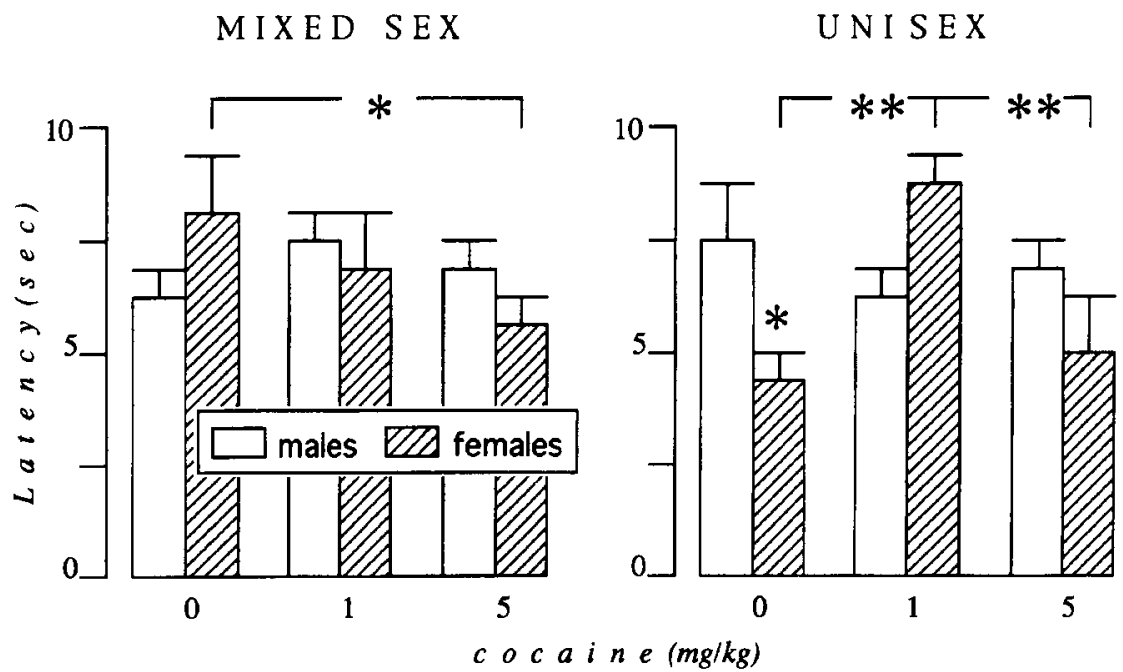

Figure 2. As assessed in a place conditioning test (drug-free state, second choice test, Day 4 of the schedule), mean latency $( \pm S E M)$ of adult male and female mice reared during prepuberty in unisex or mixed-sex family units to leave the white area. The animals were injected i.p. during conditioning training with either saline or cocaine at 1 or $5.0 \mathrm{mg} / \mathrm{kg}$. The animals were the same as those of Figure $1(n=16) .{ }^{*} p<.05 ;{ }^{* *} p<.01$.

the cocaine-paired environment (see Laviola et al., 1994; Laviola, Wood, Kuhn, Francis, \& Spear, 1995; Lett, 1988; Stewart \& Grupp, 1989). Stimuli associated with drug administration have been shown to elicit conditioned compensatory responses which resemble withdrawal-like symptoms (Siegel, 1983). As a consequence, during the second choice test in the drug-free state, the animals stayed away from the cues that elicited an aversive conditioned compensatory response. However, a different interpretation might take into account some aspects of the conditioning procedure here adopted and the nature of the temporal distance separating the habituation session and the conditioning session. Pairing of side and drug effects occurred just after habituation training (i.e., on the same day), and exposure to the to-be-conditioned experience has been shown to affect both the level and direction of conditioned performance (Kucharski, Richter, \& Spear, 1985; see also Wall, Hinson, Schmidt, Johnston, \& Streather, 1990).

Second, the shift in balance from the place aversion observed in RW subjects to a drug-conditioned preference, which was exhibited by the group of animals weaned precociously (Figure 3, lower panel on the left), might perhaps be attributed to an increment in the relative contribution of positive reinforcing properties in precociously weaned subjects after the administration of repeated psychostimulants (Lett, 1989). In fact, cross sensitization between an animal's early and actual life events and the effects of psychostimulants has also been reported (Antelman, Eichler, Black, \& Kocan, 1980; Deminiere, Piazza, Le Moal, \& Simon, 1989; Robinson, 1988; Swerdlow, Koob, Cador, Lorang, \& Hauger, 1993; for the results of developmental stress experiences, see Henry et al., 1995, and Kehoe, Triano, Rappolt, Austin-LaFrance, \& Bronzino, 1995). The present results strongly suggest that an increased sensitivity to the reinforcing effects of cocaine was found in animals that had experienced the stress of early weaning (see Cirulli, Santucci, Laviola, Alleva, \& Levine, 1994; Terranova \& Laviola, 1995).

A divergent degree of maturation or functional activity of different anatomical CNS areas, which have been shown to underlie the aversive and rewarding effects of psychostimulants (Carr \& White, 1986; see also Laviola et al., 1994), cannot be excluded in the two weaning groups (for an example of weaning-related changes in maturation of specific receptor subpopulations, see Kitchen, Crook, Muhammad, \& Hill, 1994). Relatively small differences in the sensitivity of only one of these systems may be sufficient to produce a shift in the balance between the two, with a corresponding difference in behavior. Whether the positive reinforcing or aversive effects of cocaine predominate in a given situation may depend, at least in part, on pharmacokinetic factors, and altered drug metabolism or adsorbtion (Cicero \& O'Connor, 1990; for changes in general physiological parameters, see Smith, 1991) as a function of prior weaning history also cannot be excluded. However, such an explanation, which remains speculative, has the advantage of providing some clues for the apparent paradox revealed in the present study, that is, that adult mice - as a function of their weaning history - would either approach or avoid, during a test trial without drug, the place where cocaine administration had taken place during the conditioning phase. As outlined in the introduction, the present results confirm that intraspecific changes in the time of weaning is one source of behavioral variability between individuals and may influence the subsequent course of development.

In this framework, the developmental manipulations mice underwent during prepuberty may perhaps have affected different important aspects of the animal's neural/ 

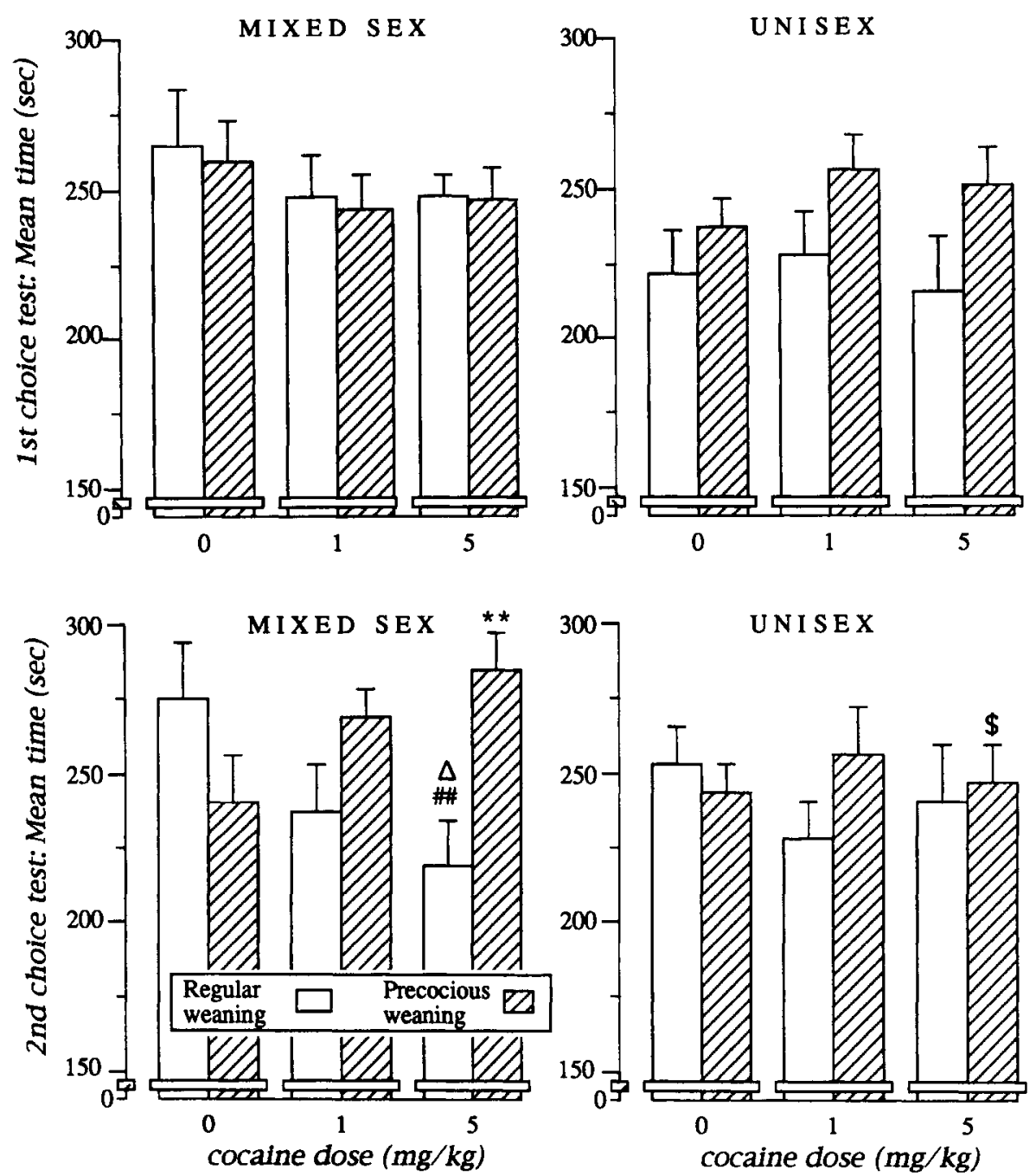

Figure 3. Mean time ( $($ SEM$)$ spent, by adult male and female mice reared in unisex or mixedsex family units, in the drug-paired side during the 10-min place conditioning test in a drug-free state-first choice test (upper panel), Day 2 of the schedule, and second choice test (lower panel), Day 4 of the schedule. The animals were injected i.p. with either saline or cocaine at 1 or $5.0 \mathrm{mg} / \mathrm{kg}$ and were the same animals used in Figures 1 and $2(n=16)$. For an elaboration of the multiple comparisons, see the Results section. ${ }^{* *} p<.01 ; \Delta p<.01$; $\# \# p .01$; ${ }^{\$} p<.01$.

behavioral profile. When compared with mixed-sex subjects, sexually segregated mice spent significantly more time in the unpaired area of the apparatus, during the second choice test (see Results). Also, a nice correlation appears when considering jointly the latency data and the time spent in the drug-paired area. In keeping with the argument that fast latencies are generally interpreted as aversion and slow latencies as preference, adult animals weaned precociously were associated both with more time spent and with longer latencies to leave the drugpaired bright and white side of the apparatus. It can be hypothesized that repeated cocaine administration may have brought about a differential expression of preference for the cues associated with the conditioning apparatus. The latter are known to be of importance for the establishment and maintenance of drug-related associative phenomena (see Laviola et al., 1992).

Prepubertal sexual segregation altered the function of monoaminergic CNS systems mediating the drug actiona neural substrate considered an important participant in an organism's responding to environmental challenge (Laviola et al., 1994) - as revealed by the restriction to mixed-sex reared mice of the modulatory effects of cocaine (see, e.g., Figure 3, lower panel on the right). This specific manipulation of rearing environment has also been related to changes in gonadal hormone regulation (Drickamer, 1992; Lupo di Prisco, Lucarini, \& Dessi'Fulgheri, 1978), and Savageau and Beatty (1981) reported that gonadectomy of male rats also affected the behavioral response to an amphetamine challenge (see 
Laviola et al., 1995). In this view, it should be noted that brain dopaminergic and adrenergic pathways are reported to play a major role in the neuroendocrine control of reproduction, and that cocaine administration has been shown to interact negatively with puberty-related processes in mice (see Chen \& Vandenbergh, 1993). Taken together, these reports indirectely suggest that interference by peripubertal sexual segregation with gonadal hormones and their metabolites on pubertal development (Drickamer 1992; Lupo di Prisco et al., 1978; Vandenbergh, 1989) of modulatory monoaminergic systems in the CNS should be considered.

In addition, by the inclusion of a group of animals removed from the mother, the present study was able to separate the potential role played by the two main factors that have been critically implicated in the genesis of the behavioral plasticity reported here (see the introduction): briefly, a biased maternal behavior, and differential sibling interactions in family units, differing for pups' gender composition. In fact, as shown in Figure 3 (lower panel on the left), a segregation-related effect was still evident in the group of animals reared in the absence of the mother. The latter finding also suggests that the period lasting from the end of the 2 nd to approximately the end of the 4th postnatal week is an important phase in development (see the introduction) for the functional organization of CNS dopaminergic systems responsible for the reinforcing properties of cocaine (see Laviola et al., 1992; Laviola et al., 1994).

As a whole, the present results confirm and extend previous observations suggesting that manipulation of social milieu, within a natural range of variation, during infancy and prepuberty (see Laviola \& Alleva, 1995; Terranova \& Laviola, 1995) is a powerful determinant of qualitative changes in sensory functions that modulate both the process of coping with slightly aversive and natural stimuli, such as a bright white area, as well as those that serve the reinforcing properties of a highly potent and addictive agent, such as cocaine. Finally, this study indicates that a wide range of individual behavioral differences are observed in a heterogeneous group of mice and that these differences can be acquired as a result of changes in the characteristics of the family unit during development. In addition, the functional deviations reported in this study discriminating high- and low-risk subpopulations, may be partially explained by variation in the sensitivity of monoaminergic CNS systems.

\section{REFERENCES}

ABbey, H., \& Howard, E. (1973). Statistical procedure in developmental studies on species with multiple offspring. Developmental Psychobiology, 6, 329-335.

Alleva, E., Caprioli, A., \& Laviola, G. (1986). Postnatal social environment affects morphine analgesia in male mice. Physiology \& Behavior, 36, 779-781.

Alleva, E., Caprioli, A., \& Laviola, G. (1989). Litter gender composition affects maternal behavior of primiparous mouse dam (Mus musculus). Journal of Comparative Psychology, 103, 83-87.

Antelman, S. M., Eichler, A. J., Black, C. A., \& Kocan, D. (1980).
Interchangeability of stress and amphetamine in sensitization. Science, 207, 329-331.

Bardo, M. T., Neisewander, J. L., \& Miller, J. S. (1986). Repeated testing attenuates conditioned place preference with cocaine. Psychopharmacology, 89, 239-243.

BowLING, S. L.. \& BARDO, M. T. (1994). Locomotor and rewarding effects of amphetamine in enriched, social, and isolate reared rats. Pharmacology, Biochemistry \& Behavior, 48, 459-464.

Bowling, S. L., Rowlett, J. K., \& Bardo, M. T. (1993). The effect of environmental enrichment on amphetamine-stimulated locomotor activity, dopamine synthesis and dopamine release. Neuropharmacology, 32, 885-893.

Boyle, A. E., Gill, K., Smith, B. R., \& Amit, Z. (1991). Differential effects of an early housing manipulation on cocaine-induced activity and self-administration in laboratory rats. Pharmacology, Biochemistry \& Behavior, 39, 269-274.

CARR, G. D., \& WhITE, N. M. (1986). Anatomical dissociation of amphetamine's rewarding and aversive effects: An intracranial microinjection study. Psychopharmacology, 89, 340-346.

CHEN, C. J., \& VANDENBERGH, J. G. (1993). Cocaine attenuates puberty acceleration in female house mice. Pharmacology, Biochemistry \& Behavior, 44, 281-285.

Chiarotti, F., Alleva, E., \& Bignami, G. (1987). Problems of test choice and data analysis in behavioral teratology: The case of prenatal benzodiazepines. Neurobehavioral Toxicology \& Teratology, 9 , 179-186.

Cicero, T. J., \& O'Connor, L. H. (1990). Abuse liability of anabolic steroids and their possible role in the abuse of alcohol, morphine, and other substances. In G. C. Lin \& L. Erinoff (Eds.), Anabolic steroid abuse (NIDA Research Monographs, Vol. 102, pp. 1-28; DHHS Publication No. ADM 90-1720). Washington, DC: U.S. Government Printing Office.

Cirulit, F., Santucci, D., Laviola, G., Alleva, E., \& Levine, S. (1994). Behavioral and hormonal responses to stress in the newborn mouse: Effects of maternal deprivation and chlordiazepoxide. Developmental Psychobiology, 27, 301-316.

Deminiere, J. M., Piazza, P. V., Le Moal, M., \& Simon, H. (1989). Experimental approach to individual vulnerability to psychostimulant addiction. Neuroscience \& Biobehavioral Reviews, 13, 141-147.

DENENBERG, V. H., \& MorTON, J. R. (1964). Infantile stimulation, prepubertal sexual-social interaction, and emotionality. Animal Behaviour, 12,11-13.

DriCKAMER, L. C. (1992). Pre- and post-weaning excretion of pubertyinfluencing chemosignals in house mice. Developmental Psychobiology, 25, 1-16.

Gray, J. A., LEAN, J., \& KeyNES, A. (1969). Infant androgen treatment and adult open-field behaviour: Direct effects of injections to siblings. Physiology \& Behavior, 4, 177-181.

Greenough, W. T., Whiters, G. S., \& Wallace, C. S. (1990). Morphological changes in the nervous system arising from behavioral experience: What is the evidence that they are involved in learning and memory? In L. R. Squire \& E. Lindenlaub (Eds.), The biologv of memory (Symposia Medica Hoechst 23, pp. 159-185). Stuttgart/New York: Schattauder.

Hayashi, S., \& Kimura, T. (1978). Effects of exposure to males on sexual preference in female mice. Animal Behaviour, 26, 290-295.

Henry, C., Guegant, G., Cador, M., Arnauld, E., Arsaut, J., Le Moal, M., \& Demotes-Mainard, J. (1995). Prenatal stress in rats facilitates amphetamine-induced sensitization and induces longlasting changes in dopamine receptors in the nucleus accumbens. Brain Research, 685, 179-186.

Kehoe, P., \& Boylan, C. B. (1992). Cocaine-induced effects on isolation stress in neonatal rats. Behavioral Neuroscience, 106, 374379.

Kehoe, P., Triano, L., Rappolt, G., Austin-Lafrance, R., \& BronZINO, J. (1995, May). Neonatal isolation results in behavioral sensitization both immediately following stress and later in adulthood. Paper presented at the 4 th International Behavioral Neuroscience Society Conference, Santiago de Compostela, Spain.

Kitchen, I., Crook, T. J., Muhammad, B. Y., \& Hill, R. G. (1994). Evidence that weaning stimulates the developmental expression of a 
delta-opioid receptor subtype in the rat. Developmental Brain Research, 78, 147-150.

KuCharski, D., Richter, N. G., \& Spear, N. E. (1985). Conditioned aversion is promoted by memory of $\mathrm{CS}-$. Animal Learning \& Behavior, 13, 143-151.

LAVIOLA, G. (1994, November), Early manipulation of social variables affects cocaine conditioned place preference in adult mice. Paper presented at the International Society for Developmental Psychobiology, Islamorada, FL.

Laviola, G., \& Alleva, E. (1995). Sibling effects on the behavior of infant mouse litters (Mus domesticus). Journal of Comparative Psychology, 109, 68-75.

Laviola, G., Dell'Omo, G., Alleva, E., \& Bignami, G. (1992). Ontogeny of cocaine hyperactivity and conditioned place preference in mice. Psychopharmacology, 107, 221-228.

Laviola, G., Dell'Omo, G., Chiarotti, F., \& Bignami, G. (1994). $d$-Amphetamine conditioned place preference in developing mice: Relations with changes in activity and stereotypies. Behavioral Neuroscience, 108, 514-524.

LAVIOLA, G., \& LoGGI, G. (1992). Sexual segregation in infancy and bidirectional benzodiazepine effects on hot-plate response and neophobia in adult mice. Pharmacology, Biochemistry \& Behavior, 42 , 865-870.

Laviola, G., Renna, G., Bignami, G., \& Cuomo, V. (1988). Ontogenetic and pharmacological dissociation of various components of locomotor activity and habituation in the rat. International Journal of Developmental Neuroscience, 24, 431-438.

Laviola, G., Wood, R. D., Kuhn, C., Francis, R., \& Spear, L. P. (1995). Cocaine sensitization in periadolescent and adult rats. Journal of Pharmacology \& Experimental Therapeutics, 275, 345-357.

LETT, B. T. (1988). Enhancement of conditioned preference for a place paired with amphetamine produced by blocking the association between place and amphetamine-induced sickness. Psychopharmacology, 95, 390-394.

LETT, B. T. (1989). Repeated exposures intensify rather than diminish the rewarding effects of amphetamine, morphine, and cocaine. Psychopharmacology, 98, 357-362.

LogGi, G., Dell'Omo, G., \& Laviola, G. (1996). Individual differences in response to psychological stress and chlordiazepoxide in adult mice: Relations with changes in early social milieu. Psychobiology, 24, 147-153.

Lupo di Prisco, C., Lucarini, N., \& Dessi'-Fulgheri, F. (1978). Testosterone aromatization in rat brain is modulated by social environment. Physiology \& Behavior, 20, 345-348.

Matthews, K., Wilkinson, L. S., \& Robbins, T. W. (1996). Repeated maternal separation of preweanling rats attenuates behavioral responses to primary and conditioned incentives in adulthood. Physiology \& Behavior, 59, 99-107.

MOORE, C. L., \& MORELLI, G. A. (1979). Mother rats interact differently with male and female offspring. Journal of Comparative Psychology, 93, 677-684.
RoBinson, T. E. (1988). Stimulant drugs and stress: Factors influencing individual differences in the susceptibility to sensitization. In P. W. Kalivas (Ed.), Sensitization in the central nervous system (pp. 145 173). New York: Academic Press.

Sahakian, B., Robbins, T. W., Morgan, M. J., \& Iversen, S. D. (1975). The effects of psychomotor stimulants on stereotypy and locomotor activity in socially-deprived and control rats. Brain Research, 84, 195-205.

SaVAGEau, M. M., \& BeatTY, W. W. (1981). Gonadectomy and sex differences in the behavioral responses to amphetamine and apomorphine of rats. Pharmacology, Biochemistry \& Behavior, 14, 17-21.

Sherman, J. E., Roberts, T., Roskam, S. E., \& Holman, E. W. (1980). Temporal properties of the rewarding and aversive effects of amphetamine in rats. Pharmacology, Biochemistry \& Behavior, 13, 597-599.

SIEGEL, S. (1983). Classical conditioning in drug tolerance and drug dependence. In Y. Israel, F. B. Glaser, H. Kalant, R. E. Popham, W. Schmidt, \& R. G. Smart (Eds.), Research advances in alcohol and drug problems (Vol. 7, pp. 207-246). New York: Plenum.

SMITH, E. F. S. (1991). The influence of nutrition and postpartum mating on weaning and subsequent play behaviour of hooded rats. Animal Behaviour, 41, 513-524.

STEWART, R. B., \& GrUPP, L. A. (1989). Conditioned place aversion mediated by self-administered ethanol in the rat: A consideration of blood ethanol levels. Pharmacology, Biochemistry \& Behavior, 32. 431-437.

SWERdLow, N. R., KoOB, G. F., Cador, M., LoRang, M., \& HaUger, R. (1993). Pituitary-adrenal axis responses to acute amphetamine in the rat. Pharmacology, Biochemistry \& Behavior, 45, 629-637.

Terranova, M. L., Alleva, E., \& Laviola, G. (1994). Affiliation and neophobia in developing mice prenatally exposed to oxazepam. $B e$ havioural Pharmacology, 5, 52-60.

Terranova, M. L., \& Laviola, G. (1995). Individual differences in mouse behavioural development: Effects of precocious weaning and ongoing sexual segregation. Animal Behaviour, 50, 1261-1271.

VANDENBERGH, J. G. (1989). Coordination of social signals and ovarian function during sexual development. Journal of Animal Science, 67, 1841-1847.

Wall, A., Hinson, R. E., Schmidt, E., Johnston, C., \& Streather, A. (1990). Place conditioning with $d$-amphetamine: The effect of the CS-UCS interval and evidence of a place avoidance. Animal Learning \& Behavior, 18, 393-400.

WILCOX, R. R. (1987). New statistical procedures for the social sciences. Hillsdale, NJ: Erlbaum.

WINN, P. (1994). Schizophrenia research moves to the prefrontal cortex. Trends in Neurosciences, 17, 265-268.

(Manuscript received September 27, 1996; revision accepted for publication January $21,1997$. 